\title{
Development of generic scenarios of industrial accidents triggered by floods: a first step toward decreasing the vulnerability of industrial facilities
}

\author{
C. El Hajj, E. Piatyszek \& V. Laforest \\ Ecole Nationale Supérieure des Mines de Saint-Etienne, France
}

\begin{abstract}
Interactions between natural events and industrial installations may lead to dangerous phenomena such as: fires, explosions, or toxic dispersions. The industrial sector is often unprepared for these Natech events, increasing its vulnerability. The final purpose of this study is to help industrial facilities to decrease their vulnerability to accidents triggered by floods. In order to attain this objective, the present article deals with the development of reference bowties that reconfigure the scenarios of these accidents. According to bibliographical research, Natech events are mainly caused by the releases of hazardous materials. This means that flood water can affect numerous parts of an industrial installation but only equipment in which hazardous substances can be found, are critical: storage units, process units and pipe networks. It is their damage that causes the LOC (Loss of Containment), responsible for generating dangerous phenomena. Studies on past accidents also showed that depending on the levels of flood severity, flood water can cause different categories of structural damage to critical equipment and thus affect the intensity of the LOC. Consequently, for each critical equipment identified, a list of structural damages (critical events) is associated depending on three levels of flood severity. Then, for each critical event, a bow-tie is elaborated. The development of nine generic bow-ties is the first step of a three step methodology of risk assessment aiming at the development of a checklist to be used in order to decrease the vulnerability of facilities to accidents triggered by floods.

Keywords: Natech, accidents triggered by floods, hazmat, loss of containment, bow-tie, critical event, dangerous phenomenon.
\end{abstract}




\section{Introduction}

There is growing evidence that the interaction between natural disasters and industrial installations can trigger technological accidents. The impacted facilities are generally located in urbanized areas which threatened not only the environment but also health and lives of large number of people [1].

Studies of the interaction between natural and technological disasters have attracted growing attention in the last decade. These conjoint disasters are referred to in the literature as natural-technologic or Na-tech events. For the purpose of this article a Natech event is defined as the possible impact of a natural hazard on all or a part of an industrial plant; impact that can initiate accident scenarios which consequences may affect the surroundings of the industrial site: environment, people and their properties [2].

Even though awareness of Natech risks is increasing within competent authorities, there is still little information available on the dynamics of Natech accidents and a lack of guidance for operators on how Natech risk reduction should be achieved. The European Seveso II Directive is an example on how chemical-accident prevention regulations address in detail the control of major accident hazards but mention indirectly the Natech risks [3].

The lack of information on dynamics of Natech accidents could be explained by the lack of detailed information on the occurrence of these events which indicates a lack of standardized reporting and record keeping. This is why the JRC (Joint Research Center Ispra, Italy) has launched a special Natech database that helps to improve the understanding of the causes, the evolution and the potential consequences of Natech events [4].

The scarcity of basic information has resulted in a low level of Natech prevention [1] and therefore in the increase of the vulnerability of process industries to natural hazards. This highlights the necessity for the development of guidance on Natech risk assessment for industry in order to have effective risk reduction [3].

A recent study [4] proved that, among natural hazards, floods have the potential of causing technological disasters by initiating severe accidental scenarios. Consequently, floods should be studied as separate accident-triggering events in a process industry. However facilities, especially SMI (Small and Medium sized Industries) which can release a significant hazard potential despite their small size, often do not have human or economic expertise to carry out a detailed Natech risk assessment. In response, mitigation efforts have been done in France by reducing the vulnerability of flood-prone facilities to industrial accidents triggered by flood events. Some examples are several vulnerability assessments to floods [5-7] (in the form of checklists) that aim to help operators to restart their activity as soon as possible following the flood event. But unfortunately, technological accidents such as fires, explosions or toxic dispersions are addressed briefly without specific guidance on how to assess the vulnerability of the process industry to these events and on how to determine sufficient safeguards to be implemented. Another example is the methodology developed by the INERIS [8] for the integration of flood hazard in the risk- 
reduction process of industrial facilities. The methodology suggests performing a systematic risk analysis for each equipment that may be responsible of major technological accident following its damage by flood water. Then, it recommends the development of accidental sequences leading to dangerous phenomena and the searching for safety barriers. This methodology highlights the importance of determining the accidental scenarios in order to define effective safety barriers against floods.

This article combines both approaches presented here above. It presents a methodology of risk assessment aiming at the development of a checklist to be used in order to decrease the vulnerability of industrial facilities to accidents triggered by floods. The proposed methodology will begin by generating general reference bow-ties that reconfigure accidental scenarios triggered by flood events. Then, steps are suggested in order to adjust these bow-ties to the characteristics of a specific type of industrial activity resulting in specific activity bow-ties. Finally, a checklist is elaborated in order to assist operators in raising particular questions that aim to evaluate the vulnerability of their facility to accidents triggered by floods and to identify safety barriers to reduce this vulnerability. The present article will be dealing with the first step of the methodology by presenting the elaboration of the generic bow-ties.

\section{Methodology for the development of bow-ties as a main tool for representing general accidental scenarios triggered by floods}

A major key-point in risk assessment is the identification of possible accident scenarios. This is why we developed reference accidental scenarios triggered by floods that may be used by operators in parallel with the process of risk assessment.

The lack of standardized reporting and record keeping of Natechs makes it very difficult to find completed data on the causes, the evolution and the potential consequences of these events. Therefore, several analyses of accidents triggered by floods reported in the major industrial accident databases have been done in order to understand the dynamics of these events [4, 9].

The results of the analysis of these studies and others $[10,11]$ of past accidents were used to understand the potential hazards and the specific features of accidents triggered by floods. These studies demonstrate that floods have the potential to cause technological accidents among which the hazmat (hazardous materials) releases are considered as the most dangerous ones. The large releases of hazmat from containment systems may escalate to dangerous phenomena identified as fires, explosions or toxic dispersions. The evolution of the definition of Natech events proves the fact that hazmat releases are the main events that occur during flooding of industrial facilities: from "technological disaster triggered by any type of natural disaster" [1] to "a chemical accident caused by a natural hazard or a natural disaster" [3]. This means that flood water can affect numerous part of an industrial installation but only some equipment is critical, equipment in which hazardous substances can be found. It is mainly their 
damage that causes the LOC (Loss Of Containment), responsible of generating dangerous phenomena. Therefore, the main event (critical event) is the structural damage of critical equipment which will be responsible of the LOC possibly resulting in severe environmental pollution, explosions or fires (Natech accidents).

Studies on past accidents also shows that depending on levels of flood severity (water height and velocity), flood water can cause different categories of structural damage to critical equipment and thus affect the intensity of the LOC.

The bow-tie is an adapted tool to represent all these characteristics of scenarios triggered by floods. Consequently, for each critical equipment identified, a list of structural damages (critical events) can be associated, depending on levels of flood severity, and corresponding release categories identified. Therefore, for each critical event associated to critical equipment, a bow-tie can be elaborated: fault trees representing the causes of the critical events and event trees their consequences that depend on the intensity of the LOC (A general scheme of the bow-tie is illustrated in figure 1).

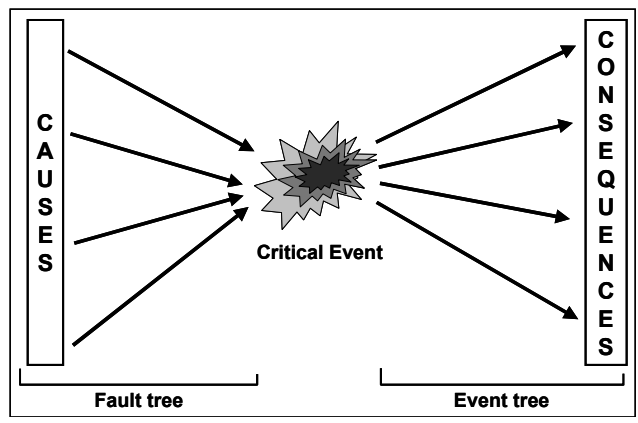

Figure 1: General scheme of bow-tie, extracted from the ARAMIS project [12].

The past accident studies presents the accidental scenarios that are expected to follow the releases (right side of the bow-ties). The analysis of these scenarios leads to the development of the event trees of the bow ties representing the possible consequences of the critical events.

Moreover, the releases of hazmat may result either by direct or indirect flood effects. In order to fill the gaps related to the scarcity of information regarding the possible causes of critical events (left side of the bow-ties), conventional risk analyses of technological accidents were used to determine which of the internal failures that might cause structural damages to critical equipment can be triggered by flood water. In order to be as exhaustive as possible, generic fault trees developed in the basis of a methodology proposed by the INERIS for the development of accidental risk assessment for industries in the context of Seveso II Directive (ARAMIS) were used [12]. Then, the fault trees of the bow ties presenting the possible causes of the critical events were elaborated. 
The generic bow-ties obtained by associating the fault trees and the event trees, can be modified in order to be adapted to specificities of a certain type of activity. They could be used for the elaboration of checklists, as a support for the reduction of the vulnerability of the facility to accidents triggered by flood events. According to the specific conditions of an activity, some branches could be removed or added. In order to obtain effective specific activity bow-ties, a systematic methodology would be complementary to the generic accidental scenarios suggested and will be presented in some future work.

\section{Results and discussion}

\subsection{Structural damages of critical equipment and release category}

As explained in the previous section, critical equipment capable of generating dangerous phenomena is identified as containing hazardous substances. ARAMIS project [12] gives a list of the critical equipment that might be found in an industrial facility. They are divided into several functional units of the industry: storage units, (un)loading units, pipe networks and process units. For the purpose of this article, we will only be considering the critical equipment presented in table 1, representing some of the equipment proposed by ARAMIS and corresponding to the equipment categories most frequently damaged by floods according to studies of past accidents [9].

Table 1: Types of critical equipment considered in this study.

\begin{tabular}{|c|l|l|}
\hline Functional unit & Type of critical equipment & \multicolumn{1}{|c|}{ Description } \\
\hline Storage unit & Atmospheric storage & $\begin{array}{l}\text { Storage tanks at ambient temperature and } \\
\text { pressure and containing substances in liquid } \\
\text { state }\end{array}$ \\
\hline Process unit & Atmospheric reactors & $\begin{array}{l}\text { Equipment of the process units, working at } \\
\text { ambient temperature and pressure and the } \\
\text { substance involved is in liquid state }\end{array}$ \\
\hline Process unit & Intermediate storage & $\begin{array}{l}\text { Storage equipment which can be found inside } \\
\text { a process unit: atmospheric storage in liquid } \\
\text { state }\end{array}$ \\
\hline Pipe network & Pipes & $\begin{array}{l}\text { The entire pipe network: Linking different } \\
\text { functional units and inside a unit between } \\
\text { different equipment, carrying substances in } \\
\text { liquid state. }\end{array}$ \\
\hline
\end{tabular}

Studies on past accidents triggered by floods [4, 9-11] also show that depending on levels of flood severity, flood water can induce different categories of structural damage to critical equipment. Therefore, building on the French land-use planning for the flood-prone areas (in French: PPRi: Plan de Prévention du Risque inondation) that produced intensity scales for the flood hazard, we divided the flood hazard severity into three classes: low, intermediate and high. The severity classes are defined by two parameters: water height and water velocity (table 2). 
Table 2: Classes of flood hazard severity, adopted from the PPRi document [13].

\begin{tabular}{|c|c|c|c|}
\hline $\begin{array}{l}\text { Water velocity } \\
\text { Water height } \\
(\mathrm{H})\end{array}$ & $\begin{array}{c}\text { Low } \\
\text { (storage of water) } \\
\mathrm{V}<0.2 \mathrm{~m} / \mathrm{s}\end{array}$ & $\begin{array}{c}\text { Intermediate } \\
\text { (flow of water) } \\
0.2 \mathrm{~m} / \mathrm{s}<\mathrm{V}<0.5 \mathrm{~m} / \mathrm{s}\end{array}$ & $\begin{array}{c}\text { High } \\
\text { (large flow of water) } \\
\mathrm{V}>0.5 \mathrm{~m} / \mathrm{s}\end{array}$ \\
\hline $\mathrm{H}<0.5 \mathrm{~m}$ & Low & Intermediate & High \\
\hline $0.5 \mathrm{~m}<\mathrm{H}<1 \mathrm{~m}$ & Intermediate & Intermediate & High \\
\hline $\mathrm{H}>1 \mathrm{~m}$ & High & High & High \\
\hline \multicolumn{2}{|r|}{} \\
\hline
\end{tabular}

The different categories of structural damage to critical equipment affect the intensity of the release of hazmat, according to the studies of past accidents [9, $11,12]$. Consequently, three release categories (intensity of LOC) are identified: R1: The instantaneous release of the complete inventory; R2: The continuous release of the complete inventory in a limited time lapse; R3: Minor leaks. The intensity of the LOC, represented by the release categories (R), will impact the final dangerous phenomena.

Table 3 presents the different structural damages considered in this study, in respect to the three classes of flood severity and the corresponding release categories presented here above.

\subsection{Fault trees: possible causes of the critical events}

The methodology proposes a fault tree for each critical event associated to critical equipment. This section aims to give some information about the content of the fault trees.

But first, it is important to note that almost all studies of past Natech present the accidental scenarios that are expected to follow the releases of hazmat. Only scarce information regarding the possible causes of critical events, hence the scenarios that precede them, is available.

The critical events (structural damages to critical equipment) may result either from direct or indirect flood effects. Direct flood effects (on a critical equipment item) are the consequences of floodwaters or floating materials in the floodwaters on a critical equipment item, capable of causing structural damages to the critical equipment considered. They correspond to shock waves that are the results of: impact of the flood water with the critical equipment; impact of floating debris in floodwaters with the critical equipment; impact of floating objects or industrial equipment with the critical equipment; impact with adjacent equipment. Indirect flood effects (on a critical equipment item) are the consequences of floodwaters or floating materials in the floodwaters on other equipment and capable of causing structural damages to the critical equipment considered. They are: Failure of the control systems that can lead to the overfilling or the overheating of the critical equipment item followed by mechanical stress; failure of electrical equipment that might cause heat waves or fires damaging critical equipment; domino effects of the final dangerous phenomena fires and explosions that can cause heat waves, shock waves, 
Table 3: $\quad$ Structural damages experienced by critical equipment and their corresponding release categories, in respect of different classes of flood severity.

\begin{tabular}{|c|c|c|c|}
\hline $\begin{array}{c}\text { Level of flood } \\
\text { severity }\end{array}$ & $\begin{array}{l}\text { Structural } \\
\text { damages }\end{array}$ & Description of the structural damages & $\begin{array}{l}\text { Release } \\
\text { category }\end{array}$ \\
\hline Low & - & - & \\
\hline \multirow[t]{3}{*}{ Intermediate } & $\begin{array}{l}\text { Breach on shell } \\
\text { (Large, } \\
\text { Medium, Small) }\end{array}$ & $\begin{array}{l}\text { Hole on the shell of the equipment, leading to a } \\
\text { continuous release. The damage is mainly } \\
\text { caused by the debris or the floating objects in } \\
\text { floodwaters. The hole can have different } \\
\text { dimensions depending on the impacting objects. }\end{array}$ & $\mathrm{R} 2, \mathrm{R} 3$ \\
\hline & $\begin{array}{l}\text { Leak from pipe } \\
\text { (Medium, } \\
\text { Small) }\end{array}$ & $\begin{array}{l}\text { Hole in the pipe, leading to a continuous } \\
\text { release. The damage is mainly caused by debris } \\
\text { or floating objects in floodwaters. The medium } \\
\text { leak is associated to the partial bore rupture of a } \\
\text { large diameter pipe; the small leak is associated } \\
\text { to the full-bore rupture of a small diameter pipe. }\end{array}$ & R2, R3 \\
\hline & $\begin{array}{l}\text { Drowning of } \\
\text { the equipment }\end{array}$ & $\begin{array}{l}\text { Outburst of a liquid substance due to the entry } \\
\text { of floodwaters in an open top tank or reactor. }\end{array}$ & $\mathrm{R} 2$ \\
\hline \multirow[t]{4}{*}{ High } & $\begin{array}{l}\text { Catastrophic } \\
\text { rupture }\end{array}$ & $\begin{array}{l}\text { Spill of the entire equipment leading to the } \\
\text { complete and instantaneous release of the } \\
\text { substance in liquid phase. The overturning of } \\
\text { equipment is mainly due to the force of flowing } \\
\text { water. }\end{array}$ & $\mathrm{R} 1$ \\
\hline & $\begin{array}{c}\text { Breach on shell } \\
\text { (Large, } \\
\text { Medium) }\end{array}$ & $\begin{array}{l}\text { Hole on the shell of the equipment, leading to a } \\
\text { continuous release. The damage is mainly } \\
\text { caused by floating of the equipment due to the } \\
\text { force of flowing water and its impact with other } \\
\text { equipment. }\end{array}$ & $\mathrm{R} 2$ \\
\hline & $\begin{array}{l}\text { Leak from pipe } \\
\text { (Large, } \\
\text { Medium, Small) }\end{array}$ & $\begin{array}{l}\text { Hole in the pipe, leading to a continuous } \\
\text { release. The damage is mainly caused by } \\
\text { floating equipment in floodwaters or the force } \\
\text { of flowing water. The large leak is associated to } \\
\text { the full-bore rupture of a large diameter pipe; } \\
\text { the medium leak is associated to the partial bore } \\
\text { rupture of a large diameter pipe; the small leak } \\
\text { is associated to the full-bore rupture of a small } \\
\text { diameter pipe. }\end{array}$ & $\mathrm{R} 2, \mathrm{R} 3$ \\
\hline & $\begin{array}{l}\text { Drowning of } \\
\text { the equipment }\end{array}$ & $\begin{array}{l}\text { Outburst of a liquid substance due to the entry } \\
\text { of floodwaters in an open top tank or reactor. }\end{array}$ & $\mathrm{R} 2$ \\
\hline
\end{tabular}

missiles, fall of structuring elements [14] triggering structural damage to equipment. Therefore, the fault trees are divided into two parts in order to represent these flood effects. An example of a fault tree for the critical event "large breach on shell" is shown in figure 2.

Consequently, each critical event was associated to one fault tree that considers direct flood effects due to one or several levels of flood severity and indirect flood effects. 


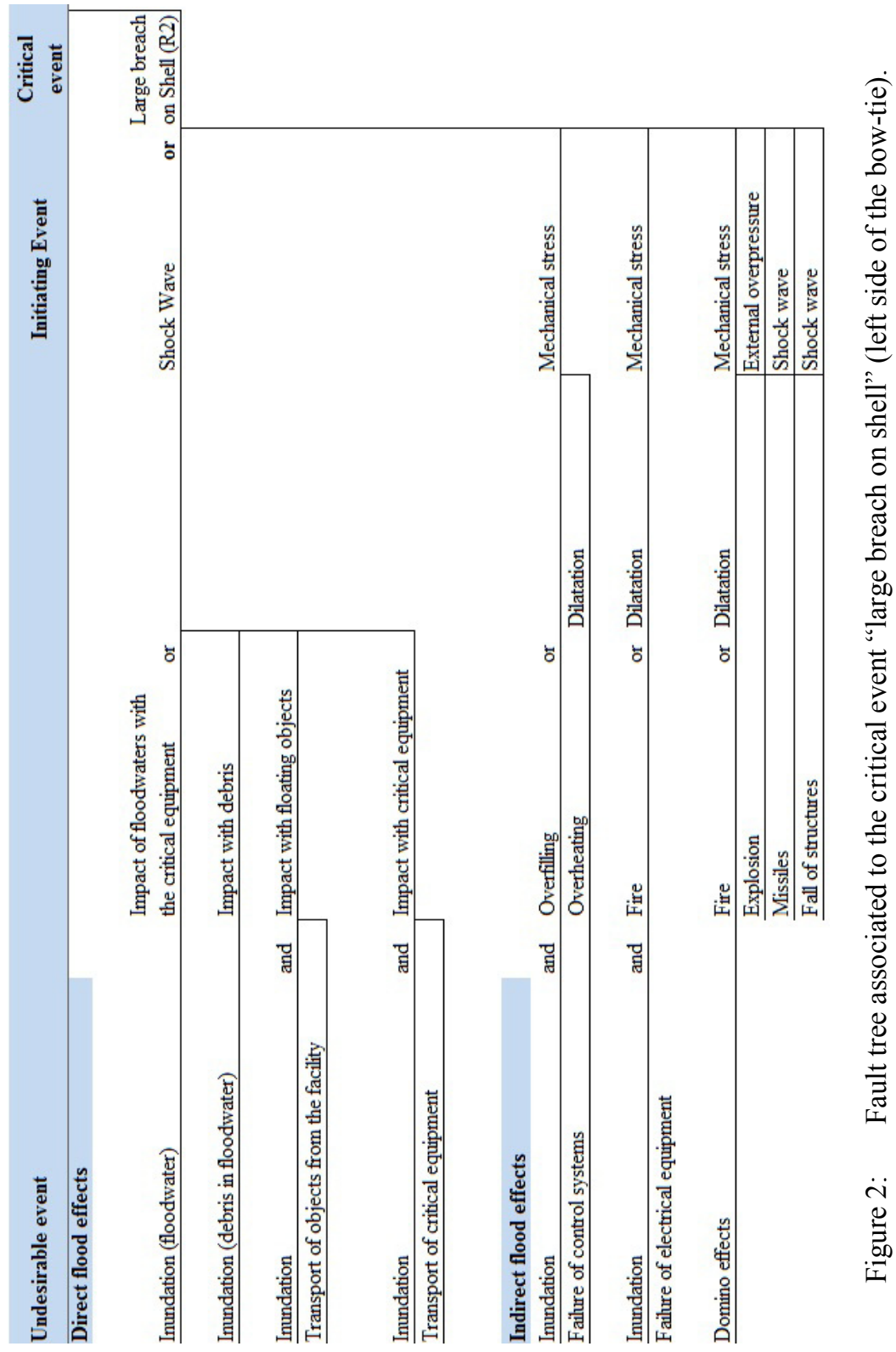




\subsection{Event trees: Possible consequences of the critical events}

Each critical event can trigger only one type of release category that impacts the scenarios following the release of hazmat. Therefore, each critical event has one possible event tree.

In the case of our study, the most frequently occurring final scenario is water contamination. This is due to the spreading of the released toxic substances by the floodwaters over large areas and therefore causing pollution of surface water, groundwater and soil [15].

Other flood-triggered accident scenarios were fires, explosions and toxic cloud dispersion. These scenarios are typical of the process industry due to the handling of toxic and flammable materials. But they can also be initiated by specific causes of flooding of industrial facilities due to the presence of water: If substances reacting with water are involved, flammable and toxic gases can be generated. These gaseous releases can, in turn, trigger further fires, explosions and toxic cloud dispersions [9]. This means that beside conventional scenarios, it is necessary to take into account the scenarios due to the release of substances reacting with water.

Also since domino effects (fires, explosions...) resulting from dangerous phenomena are included in the causes of critical events, it is interesting to additionally consider final scenarios that can be due to hazardous substances reacting with fires and explosions.

Therefore, the final scenarios depend on the hazardous properties of the released substances $[4,9,11,12,15]$, in addition to the intensity of LOC as mentioned earlier. For the purpose of this study, four hazardous properties are considered: flammable, toxic, reacting with water and reacting with fires and explosions. The event trees will be divided into four branches; one for each hazardous property.

The event trees will take also into consideration some LOC conditions $[9,12$, $14]$, as shown in figure 3.

\subsection{Bow-ties: associated to each critical event}

Afterwards, each bow-tie is obtained by the association of a critical event linked to critical equipment, its corresponding fault tree on the left and its corresponding event tree on the right.

Given the large size of the obtained bow-ties, a general bow-tie that summarizes some of the information presented in the previous paragraphs is shown in figure 4.

The result of this study is the development of nine generic bow-ties that reconfigure accidental scenarios triggered by flood events, assuming that preventive and protective measures are not installed or that they are ineffective. These bow-ties represent the first step of a three step methodology of risk assessment aiming at the development of a checklist to be used in order to decrease the vulnerability of industrial facilities to accidents triggered by floods. 


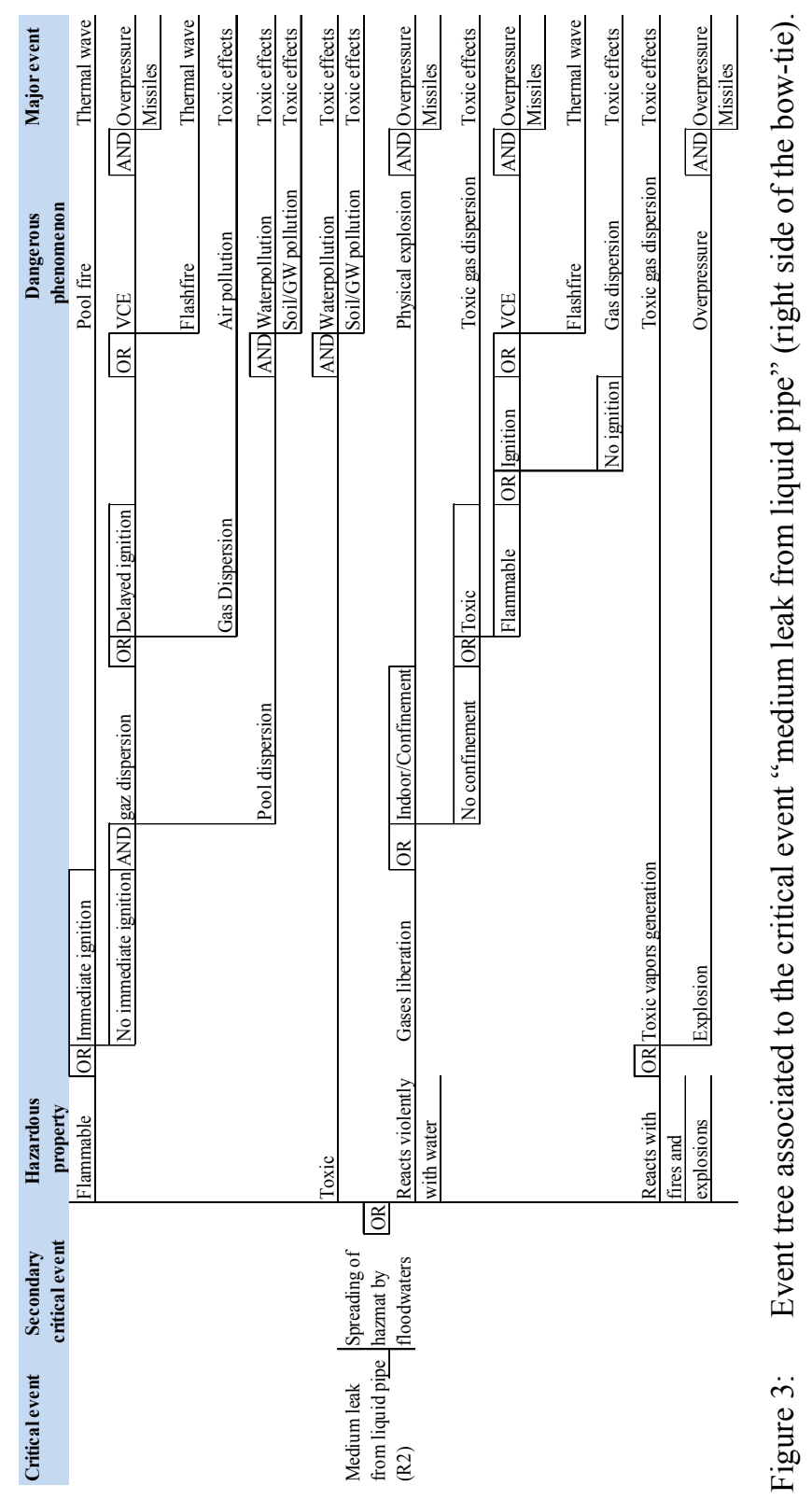




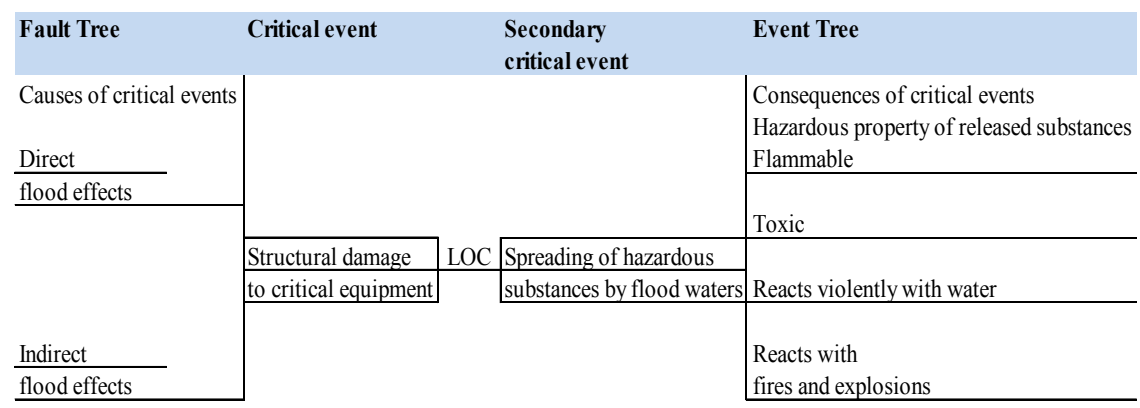

Figure 4: General model of the final bow-ties obtained.

\section{Conclusion}

Generic bow-ties reconfiguring technological accidental scenarios triggered by flood events have been developed in order to help understanding the mechanisms of these industrial accidents. These bow-ties have been designed as a first step of a three step methodology consisting on the development of a checklist to be used in order to decrease the vulnerability of industrial facilities to these accidents. Moreover, the bow-ties provided can be used as reference scenarios in any risk assessment that intends to take the flood hazard into consideration. It is a sufficient tool for risk reduction that helps to find effective protective and preventive measures to implement in the industrial plant. The difficulty of this study was mainly related to the lack of reported accidents and lessons learned addressing the causes, evolutions and consequences of such events.

\section{References}

[1] Cruz, A.M., Steinberg, L., Vetere Arellano, A.L., Nordvik, J.P., and Pisano, F. State of the art in Natech Risk Management, Joint Research Center Report, 2004.

[2] Vallée, A., Duval, C. and Reimeringer, M., Personal communication 4 October 2011, Présentation des travaux INERIS sur la prise en compte du risque inondation au niveau des installations industrielles à risques (French), Natech Seminar 2011, Haute-Alsace University, Mulhouse, France.

[3] Kraussmann, E., Natech Risk Reduction in OECD Member Countries: Results of a questionnaire Survey. OECD Workshop Proceedings - Natech risk management. Dresden, Germany, pp. 9-11, May 23, 2012.

[4] Kraussmann, E. and Mushtaq, F., A qualitative Natech damage scale for the impact of floods on selected industrial facilities. Natural Hazards, 46, pp. 179-197, 2008.

[5] Mangual, P.G., Thesis: Contribution à la caractérisation de la vulnérabilité des PME-PMI aux inondations: Vers un instrument méthodologique 
d'autodiagnostic (French). Ecole des mines de Paris - Sophia Antipolis, 2005.

[6] Démarche industrielle (French), www.plan-loire.fr/fr/les-platesformes/prevention-des-inondations/demarche-industrielle/index.html.

[7] Ledoux, B., Guide pour la Conduite des Diagnostics des Vulnérabilités aux Inondations pour les Entreprises Industrielles (French), 2000.

[8] Ayrault, N. and Bolvin, C., Analyse des risques et prévention des accidents majeurs - Rapport partiel d'opération f: Guide pour la prise en compte du risque inondation (French), INERIS Report, 2004.

[9] Cozzani, V., Campedel, M., Renni, E. and Kraussmann, E., Industrial accidents triggered by flood events: Analysis of past accidents. Journal of hazardous materials, 175, pp. 501-509, 2010.

[10] Vallée, A., and Dolladille, O., Impact des inondations du Sud-Est (septembre 2002) sur les activités présentant un risque technologique Rapport partiel d'opération $f$. INERIS Report, 2003.

[11] Renni, E., Basco, A., Busini, V., Cozzani, V., Kraussman, E., Rota, R. and Salzano, E., Awareness and mitigation of Natech accidents: Toward a methodology for risk assessment, Internal document.

[12] De Dianous, V., Vallée, A., Prats, F., Rodrigues, N. and Hourtolou, D., ARAMIS: Développement d'une méthode intégrée d'analyse des risques pour la prévention des accidents majeurs (French). INERIS Report, 2004.

[13] Ministère de l'aménagement du territoire et de l'environnement, et Ministère de l'équipement, des transports et du logement. Guide méthodologique: Plans de prévention des risques naturels (PPR) Risques d'inondation (French).

[14] Khan, F.I. and Abbasi, S.A., Models for domino effect analysis in chemical process industries. Process Safety Progress, 1998.

[15] Kon, E., Salzano, E., Kraussman, E. and Reimeringer, M., Methodological issues: screening of vulnerability and analysis of Natech accidental risk. SP1 Subproject: iNTeg-Risk Emerging Management Framework (ERMF): New Paradigm, Methods and tools for dealing with Emerging Risks. 